\title{
Fostering Distance Education: Lessons From a United States-England Partnered Collaborative Online International Learning Approach
}

\author{
Lucy A. Ingram ${ }^{1 *}$, Courtney Monroe ${ }^{1}$, Hayley Wright $^{2}$, Amy Burrell $^{3}$, Rebecca Jenks ${ }^{2}$, \\ Simon Cheung ${ }^{2}$ and Daniela B. Friedman ${ }^{1}$
}

${ }^{1}$ Department of Health Promotion, Education and Behavior, University of South Carolina, Columbia, SC, United States, ${ }^{2}$ Health and Life Sciences, Coventry University, Coventry, United Kingdom, ${ }^{3}$ Institute for Global Innovation, University of Birmingham, Birmingham, United Kingdom

\section{OPEN ACCESS}

Edited by:

Anabela Carvalho Alves, University of Minho, Portugal

Reviewed by: José Manuel Oliveira, University of Aveiro, Portugal Sonia Gomez, Eindhoven University of Technology, Netherlands

*Correspondence: Lucy A. Ingram Lannang@sc.edu\&hairsp

Specialty section: This article was submitted to Higher Education, a section of the journal Frontiers in Education

Received: 24 September 2021 Accepted: 11 November 2021 Published: 01 December 2021

Citation: Ingram $L A$, Monroe $C$, Wright $H$, Burrell $A$, Jenks $R$, Cheung $S$ and Friedman DB (2021) Fostering Distance Education: Lessons From a United States-England Partnered Collaborative Online International Learning Approach.

Front. Educ. 6:782674. doi: 10.3389/feduc.2021.782674
Collaborative Online International Learning (COIL) is a teaching and learning approach whereby entire courses or modules are co-developed and team taught by instructors from different institutions for students of both institutions. Since 2006, the approach has been gaining in mass appeal; however, considering our present-day global coronavirus pandemic, COILs have a renewed relevance in academia. Faculty from the University of South Carolina (United States) and Coventry University (England) embarked on a COIL partnership yielding a valuable experience that can serve as a model for other institutions that are interested in developing innovative and cross-cultural distance learning opportunities. The purpose of this paper is to explain how the institutional partnership emerged, describe the course content, and provide lessons that our team learned through the COIL development and implementation process. Our experience as a first-time COIL partnership is a model for others to consider as the landscape for the academic enterprise expands the confines of brick-and-mortar institutions.

Keywords: collaborative online international learning, distance education, United States, England, higher education

\section{INTRODUCTION}

Collaborative Online International Learning (COIL) is a teaching and learning paradigm that became fully coined in 2006 (Rubin, 2017), but has since developed mass appeal and a newfound relevance during our present-day global coronavirus pandemic. COILs, also known as "virtual exchanges" are models of learning and collaboration whereby entire courses or course modules are co-developed and team taught by instructors from different institutions (and most often from different cultural contexts) for students of both institutions. An essential tenet of the COIL model is the emphasis on experiential and collaborative student learning while providing students with new contextual meaning to the ideas being explored (Rubin, 2017). Other advantages include enhanced global citizenship (MenardWarwick, 2009; Hull et al., 2010; Makaramani, 2015; Orsini-Jones and Lee, 2018; King de Ramirez, 2019) and intercultural exchange (Belz and Thorne, 2006; Guth and Helm, 2010; De Castro et al., 2019). Faculty from the University of South Carolina (United States) and Coventry University (England) developed and implemented a COIL yielding a valuable experience that can serve as a model for other institutions that are interested in developing innovative and cross-cultural distance learning opportunities. 
In 2018, a faculty researcher from Coventry University (CU) invited faculty members from the University of South Carolina (UofSC) to deliver a symposium at CU on cognitive and sexual health and opportunities for collaborative discourse about healthy aging based on their prior research (Annang et al., 2011; Friedman, Marquez, and Fernandez, 2013; Rose et al., 2013; Annang et al., 2014; Bergeron et al., 2016; Fletcher et al., 2016; Friedman et al., 2016; Jackson et al., 2016; Soltani et al., 2017; Tang et al., 2017). Co-author (name withheld) obtained grant funding to support the symposium based on her work on sex in the media and the resultant media attention that she received (Wright and Jenks, 2016; Wright et al., 2017). During that visit, the UofSC faculty members, as well as a team of CU faculty members collaborated to develop a "COIL-enhanced module" (Rubin, 2017), that is, a 6-week module embedded in two courses that would focus on the international collaboration and the topical content of sex and aging in the media. The purpose of this paper is to explain how the institutional partnership emerged, describe the course content, and provide lessons that our team learned through the COIL development and implementation process.

\section{COIL COURSE OVERVIEW}

We developed a hybrid, collaborative, international learning experience where existing courses at UofSC and CU were identified to serve as the hosts of the COIL. The COIL was entitled "Sex, Lies, and Mediascape (Mis)representations across the lifespan". The classes met separately at each institution. The UofSC course (Consumer Health in Contemporary Society) was a fully asynchronous online course. The course was housed in the Arnold School of Public Health's Department of Health Promotion, Education, and Behavior as an elective available to undergraduate and graduate students. The primary course objective is to allow students to explore the relationships between consumerism, health, and education, with the ultimate goal of preparing them to make informed decisions as health consumers. The CU course (combined enrollments from two undergraduate psychology courses) was a hybrid course with face-to-face and asynchronous, online content. The course was housed in the School of Psychological, Social, and Behavioural Sciences and was required for first-year psychology students. The primary course objective was to introduce students to the process of critically analyzing health content that is presented in the media and popular culture. During the 6-week COIL module, the students and the instructors met asynchronously online. The COIL module was team developed by the instructors of the selected courses and the researchers who were part of the original sex and aging collaboration in consult with a CU learning technology specialist.

\section{COIL DEVELOPMENT}

The course planning process occurred over a 6-month period. In June 2018, our team submitted a course proposal to the CU
Centre for Global Engagement. The course proposal included information about the project leads at each institution, COIL activities and online tools used, and the methods for capturing intercultural development and assessing COIL outcomes. The objectives of the COIL were for students to 1) gain an intercultural awareness and understanding of current research into sexual health and aging and how sex and aging are portrayed in the media and 2) learn how to critically assess the quality of media messages. Shortly thereafter, we were approved to implement the COIL module to begin January 2019. During the planning process, our team communicated regularly via email and Skype about lecture content, how to engage students with the content and with each other (across the international time zones), the timing to release the COIL content, and the logistics for the shared platform that housed the COIL content. We shared lecture outlines and course syllabi. We also discussed how to introduce the idea of the collaboration with students in the UofSC and CU courses. We were sensitive to potential anxieties that could emerge from students about learning and utilizing the Open Moodle platform (a new experience for the UofSC students) and tried to preempt this with trial runs by our team and gleaning from the prior experiences of the CU team. This collaborative process was vitally important as the ultimate goal of the COIL was to integrate an international element to the students' learning outcomes, allow students to reflect upon their own and their international colleagues' cultural points of view, and to provide an opportunity to develop transferrable networking skills between UofSC and CU students. Our team modeled this approach during the course development process.

\section{COIL CONTENT}

Instructors introduced the COIL module to students as part of their standard introduction of the course. The COIL was described as being embedded in the course in which the students enrolled and would be a 6-week engagement to include content relevant to the course as well as opportunities to engage in an international and intercultural student learning experience. Additionally, a brief video was produced by the COIL instructors and lecturers to introduce themselves, welcome students to the experience, and engender some personal connection and enthusiasm for this unique opportunity. The video was housed on the Open Moodle platform for students' ease of access.

Four lectures were developed for the COIL. Two lectures were delivered by UofSC faculty and two by CU faculty. The UofSC lectures focused on media influence and media literacy. One lecture focused on healthy aging, perceptions of aging, forms of media, and media literacy. The content was framed by the Centers for Disease Control and Prevention (CDC) Healthy Aging Network definition of healthy aging (Lang et al., 2006), the Communication Predicament Model conceptual framework (Ryan et al., 1986), and the Center for Media Literacy (2020). The other lecture highlighted research about the influence of sexual images in media, particularly on youth, and included a review of several media images (Walsh-Childers et al., 2002; 
Ward, 2003; Kunkel et al., 2005; Chandra et al., 2008; Fisher et al., 2009; Morgan, 2011; Wright et al., 2012). The intended learning outcomes were for students to 1) identify factors that may influence one's perceptions and behaviors, 2) describe how to be informed consumers of media, and 3) discuss how to critically evaluate media. The $\mathrm{CU}$ lectures focused on instances where media portrayals of research were misleading. One lecture was based on the work of Wright and others on the relationship between sexual activity and cognitive function in older adults (Wright and Jenks, 2016; Wright et al., 2017). The lecture included information detailing the scientific rationale for the research and the implications for the intended audience. Additional content included examples from worldwide media coverage of the sex and cognition research, including inappropriate images and popular media misrepresentations of how the research was conducted. The other lecture focused on the "pill scare" in the United Kingdom in the early 1990s whereby the media delivered grossly distorted information to the public regarding the safety of using the contraceptive pill following a government report (Spitzer, 1997; Wood et al., 1997; Bhathena, 1998; Williams et al., 1998; Furedi, 1999; Farmer et al., 2000). The intended learning outcomes were for students to 1) question what they see in the media and 2) describe how this contributes to attitude development and behavior.

\section{COIL IMPLEMENTATION}

Each lecture was pre-recorded using narrated PowerPoint or Screencast-O-Matic and uploaded to a platform called Open Moodle (Moodle Pty Ltd., West Perth WA, Australia) that was housed at CU. The Open Moodle platform served as a centralized mechanism to allow students from each partner university to enroll in the COIL virtual learning environment without having to involve additional University-specific Registrar personnel. Instructors from UofSC and $\mathrm{CU}$ also registered on the Open Moodle module as instructors with editing rights for a true dual ownership of the pedagogic contribution to the collaborative learning resources. Additionally, technical support was available to support student and faculty needs.

The COIL was delivered during two academic terms in consecutive years (Spring 2019 and Spring 2020). A total of 550 students were enrolled across both offerings $(n=272$ in Spring 2019; $n=278$ in Spring 2020). Thirty-seven percent of the students in Spring 2019 were UofSC students which was nearly identical to the proportion of students in the Spring 2020 term (36.3\%). Across both offerings of the COIL, students were primarily undergraduate $(97.8 \%)$; however, the UofSC course was also open to graduate students.

Guided by well-established recommendations and best practices in instruction (Chickering and Gamson, 1987; Chickering and Gamson, 1991; Crews et al., 2015), in addition to the lectures, students were given online discussion prompts to facilitate initial introductions and subsequent interactive examinations of their understanding of the material delivered through lectures. For example, students were asked to identify two examples of sex in the media. For each of the images that they selected, they were to describe it, reveal if the image was overt or suggestive and provide their rationale for this decision, and describe the intended audience for the image. Opinion polls were also implemented to foster student engagement, providing a quick snapshot of students' thoughts on the presented topics. For instance, students viewed an image that corresponded with a news article summarizing recent research and were asked to indicate what they thought represented the focus of the article from a list of close-ended response options. Ten online discussion prompts and four polls were administered over the course of the 6-week COIL. Students engaged in the discussion forums as one group, meaning links to original posts were displayed in one continuous thread from the most recent one to the oldest one. Links to replies were provided alongside the original post. Students were required to submit at least one original post and encouraged to reply to other students' posts in response to each discussion prompt. This allowed students from each institution to interact and engage with one another and to share knowledge about their culture-driven perceptions. We elected to allow students to interact asynchronously, primarily due to time constraints in time zone differences. Instructors provided weekly feedback in order to further cement student learning.

We do not have ethics committee approval to include specific student comments (anonymous or otherwise). Alternatively, we present some indicators of student engagement by summarizing selected measures below. Across both offerings of the COIL, we found that $51.1 \%$ of students participated in the module polls, $38.4 \%$ of students viewed the lectures, and $32.0 \%$ of students responded to discussion posts. Given that students were "strongly encouraged" to participate in these activities, rather than "required," we found their performance was respectable.

\section{LESSONS LEARNED}

We share ten lessons learned from our COIL partnership that may be useful for others considering developing a COIL at their institutions. We found that determining the course content and learning objectives were only the beginning of the process. We offer lessons learned in COIL course development and implementation below.

\section{Development}

One of the unique factors to consider about establishing a COIL partnership is 1) establishing a memorandum of understanding between institutions to formalize the partnership. Our institutions' approval processes were seamless because of their prior commitments to COIL and internationalization of higher education. However, we understand that policies existing at other institutions may not be well established and therefore may require additional lead/processing time. 2) Secondly, accommodating global time zone differences and academic calendars is a critical component of the development phase. The time zone difference between each of our institutions was 5 hours. While we knew this at the start of our partnership, the logistics behind scheduling planning meetings and establishing timelines was 
more difficult than anticipated, particularly with the academic calendar difference. Identifying "off-limit times" (e.g., academic breaks and holidays) and working around those is advisable. 3) Also unique to the COIL experience is recognizing potential differences in learning management systems (LMS) and determining which platform(s) will be used to deliver the COIL content. Testing the platforms out for ease of use (from the student perspective) prior to course implementation was useful for our team.

Other lessons learned in development comprise logistical factors. 4) Determining one software or technique to use for recording content (e.g., narrated PowerPoint or Screencast-OMatic) would streamline the presentation to students. While there may be a learning curve with new technology, the student experience will appear more polished and symmetrical if there is a commonality in the presentation appearance and quality. Other factors to consider early during the planning process include 5) creating and adhering to a timeline for meetings and delivery of materials, and 6) establishing clear expectations of roles and responsibilities. Points five and six are particularly significant as collaborators should account for the time that it will take for content development, review by team members, and upload into the LMS to ensure equity of work distribution so that some team members are not unduly burdened.

\section{Implementation}

Regarding lessons learned in implementation, specific to our partnership experience was the use of the learning platform Open Moodle, which was selected due to its utility as a sharable platform for students across the different institutions. 7) Integrating low effort/no risk assignments to allow students to interact with the system is ideal, as well as framing the learning of the new platform around course objectives (e.g., global learning of new technologies). 8) Having access to technical support persons during the implementation phase is critical. We were able to consult with our technical support staff member regularly during the COIL implementation which helped ease anxieties about course delivery that were beyond the course content. Additionally, having persons with technical support skills as part of the planning and development phase was essential in order to understand the capabilities and limitations of the LMS, and potential software execution pitfalls to avoid. 9) Scheduling regular meetings during the implementation phase is a vital part of the successful implementation of the COIL. Obtaining formal and informal student feedback during the implementation phase can be discussed during these meetings to ensure that course objectives are being met. 10) Lastly, while not a novel concept, the end of academic terms is often frenetic with deadlines, exams, grading, and general course close out. But, we find it crucial for the team to meet at the close of the term to debrief about what worked well and what did not work well, and potentially prepare for future course offerings. As part of this meeting, we recommend reflecting on course or module objectives to determine if they have been met. If a COIL module (rather than a full course) is implemented, consider adding questions to existing course evaluations to assess if students' responses to
COIL objectives (beyond topical content) have been met. Some examples related to intercultural relations include the ability to communicate effectively and appropriately in intercultural situations, understanding the value of cultural diversity (Deardorff, 2006), sharing knowledge about one's culture and learning about others' ways of living, learning about different culturally nuanced communication styles, and developing networking and digital skills that will be attractive to future industry professionals across the globe (Coventry University, 2020).

\section{DISCUSSION}

The past year has invited renewed focus on the importance of innovation in pedagogy and reduced reliance on traditional models of teaching and learning. COILs are a teaching and learning paradigm that offer collaborative student learning opportunities as well as global, intercultural exchange, that take advantage of distance learning and technology. Prior to the COVID-19 pandemic, COILs were touted for their innovation in approach to study abroad, international learning, and global citizenship (Vahed and Rodriguez, 2020; Nava-Aguirre et al., 2019). Post-pandemic, they are even more useful as an approach to bridging learning across geographic borders (Liu and Shirley, 2021). As evidenced by their level of engagement in the COIL course material, we found that students were receptive to the idea of a crossinstitution, cross-cultural collaboration and saw it as a complement to the traditionally-delivered course content. This is in line with others who have reported that students value the COIL approach and find that it should be an option for students in higher education (De Castro et al., 2019; King Ramirez, 2020).

Another important facet of developing a COIL is an acknowledgement of the logistics involved in implementation. While it important that parties involved be enthusiastic and motivated, institutional commitment and availability of resources is a critical factor in implementation success. We found it vitally important to have support from our institutions' leadership who value academic partnership. Essentially, this helps expedite logistics such as developing and executing a memorandum of understanding and ensuring that information technology support could be made available to assist with module implementation and troubleshooting. Others have documented the challenges to executing international course design broadly (Bilous et al., 2018), and more specifically, COILs (De Castro et al., 2019). Awareness of the potential complications involved in securing institutional commitments is a vital stage in the COIL implementation process.

Our present-day reality of the coronavirus pandemic is forcing educators to consider innovative ways to keep teaching and keep students engaged in learning, and COILs may be one creative solution that simultaneously fosters intercultural appreciation and awareness. While it is a limitation that we are unable to incorporate data from student course evaluations as part of this paper, the 
aforementioned markers of student engagement clearly demonstrate students' receptivity to and interest in the COIL content and international learning aspects. Our experience as a first-time COIL partnership is a model for others to consider as the landscape for the academic enterprise expands the confines of brick-and-mortar institutions. The purpose of this paper was to describe our team's experience in developing and implementing an international, cross-cultural, cross-institution, collaborative teaching opportunity. Faculty at the UofSC and CU shared a rewarding experience, and we anticipate that others will benefit from the lessons learned from our international academic exchange.

\section{REFERENCES}

Annang, L., Hannon, L., 3rd, Fletcher, F. E., Horn, W. S., and Cornish, D. (2011). Using Nominal Technique to Inform a Sexual Health Program for Black Youth. Am. J. Health Behav. 35 (6), 664-673. doi:10.5993/ajhb.35.6.3

Annang, L., Lian, B., Fletcher, F. E., and Jackson, D. (2014). Parental Attitudes about Teenage Pregnancy: Impact on Sexual Risk Behaviour of AfricanAmerican Youth. Sex Educ. 14 (2), 225-237. doi:10.1080/ 14681811.2013.867480

Belz, J. A., and Thorne, S. L. (2006). Internet-Mediated Intercultural Foreign Language Education. Boston, MA: Thomson Heinle.

Bergeron, C. D., Friedman, D. B., Messias, D. K., Spencer, S. M., and Miller, S. C. (2016). Older Women's Responses and Decisions after a Fall: The Work of Getting "back to normal". Health Care Women Int. 37 (12), 1342-1356. doi:10.1080/07399332.2016.1173039

Bhathena, R. K. (1998). The 1995 Pill Scare and its Aftermath: Lessons Learnt. J. Obstet. Gynaecol. 18 (3), 215-217. doi:10.1080/01443619867335

Bilous, R., Hammersley, L., Lloyd, K., Rawlings-Sanaei, F., Downey, G., Amigo, M., et al. (2018). 'All of Us Together in a Blurred Space': Principles for Co-creating Curriculum with International Partners. Int. J. Acad. Develop. 23, 165-178. doi:10.1080/1360144x.2017.1412973

Center for Media Literacy (2020). Available at: http://www.medialit.org/(Accessed June 10, 2020).

Chandra, A., Martino, S. C., Collins, R. L., Elliott, M. N., Berry, S. H., Kanouse, D. E., et al. (2008). Does Watching Sex on Television Predict Teen Pregnancy? Findings from a National Longitudinal Survey of Youth. Pediatrics 122 (5), 1047-1054. doi:10.1542/peds.2007-3066

Chickering, A. W., and Gamson, Z. F. (1991). “Applying the Seven Principles for Good Practice in Undergraduate Education," in New Directions for Teaching and Learning (San Francisco, CA: Jossey-Bass), 47.

Chickering, A. W., and Gamson, Z. F. (1987). Seven Principles for Good Practice in Undergraduate Education. AAHE Bulletin, 3-7.

Coventry University (2020). Collaborative Online International Learning. Available at: https://www.coventry.ac.uk/study-at-coventry/centre-for-globalengagement/collaborative-online-international-learning-coil/(Accessed June 10, 2020).

Crews, T. B., Wilkinson, K., and Neill, J. K. (2015). Principles for Good Practice in Undergraduate Education: Effective Online Course Design to Assist Students' success. MERLOT J. Online Learn. Teach. 11 (1), 87-103.

De Castro, A. B., Dyba, N., Cortez, E. D., and Pe Benito, G. G. (2019). Collaborative Online International Learning to Prepare Students for Multicultural Work Environments. Nurse Educ. 44 (4), E1-E5. doi:10.1097/ NNE.0000000000000609

Deardorff, D. K. (2006). Identification and Assessment of Intercultural Competence as a Student Outcome of Internationalization. J. Stud. Int. Educ. 10 (3), 241-266. doi:10.1177/1028315306287002

Farmer, R. D., Williams, T. J., Simpson, E. L., and Nightingale, A. L. (2000). Effect of 1995 Pill Scare on Rates of Venous Thromboembolism Among Women Taking Combined Oral Contraceptives: Analysis of General Practice Research Database. Br. Med. J. 321 (7259), 477-479. doi:10.1136/bmj.321.7259.477

Fisher, D. A., Hill, D. L., Grube, J. W., Bersamin, M. M., Walker, S., and Gruber, E. L. (2009). Televised Sexual Content and Parental Mediation: Influences on

\section{DATA AVAILABILITY STATEMENT}

The original contributions presented in the study are included in the article/Supplementary Material, further inquiries can be directed to the corresponding author.

\section{AUTHOR CONTRIBUTIONS}

All authors listed have made a substantial, direct, and intellectual contribution to the work and approved it for publication.

Adolescent Sexuality. Media Psychol. 12 (2), 121-147. doi:10.1080/ 15213260902849901

Fletcher, F. E., Ingram, L. A., Kerr, J., Buchberg, M., Bogdan-Lovis, L., and PhilpottJones, S. (2016). "She Told Them, Oh that B!\%@h Got AIDS”: Understanding the Impact of Multi- Level HIV/AIDS-Related Stigma from the Perspectives of African American Women Living with HIV. AIDS Patient Care and STDs 30 (6), 349-356. doi:10.1089/apc.2016.0026

Friedman, D. B., Wilcox, S., and Hebert, J. R. (2016). Proposing an Interdisciplinary, Communication-Focused Agenda for Cancer and Aging Researchers. J. Cancer Educ. 31 (2), 218-220. doi:10.1007/s13187-015-0822-3

Furedi, A. (1999). The Public Health Implications of the 1995 'Pill Scare'. Hum. Reprod. Update 5 (6), 621-626. doi:10.1093/humupd/5.6.621

Hull, G. A., Stornaiuolo, A., and Sahni, U. (2010). Cultural Citizenship and Cosmopolitan Practice: Global Youth Communicate Online. English Educ. 42 (4), 331-367. doi:10.2307/23018017

Jackson, D. D., Ingram, L. A., Boyer, C. B., Robillard, A., and Huhns, M. N. (2016). Can Technology Decrease Sexual Risk Behaviors Among Young People? Results of a Pilot Study Examining the Effectiveness of a Mobile Application Intervention. Am. J. Sex. Educ. 11 (1), 41-60. doi:10.1080/ 15546128.2015.1123129

King de Ramirez, C. L. (2019). Global Citizenship Education through Collaborative Online International Learning in the Borderlands: A Case of the Arizona-Sonora Megaregión. J. Stud. Int. Educ. 25, 1-17. doi:10.1177/1028315319888886

King Ramírez, C. (2020). Influences of Academic Culture in Collaborative Online International Learning (COIL): Differences in Mexican and U.S. Students Reported Experiences. Foreign Lang. Ann. 53 (3), 438-457. doi:10.1111/ flan. 12485

Kunkel, D., Eyal, K., Finnerty, K., Biely, E., and Donnerstein, E. (2005). Sex on TV 4: A Biennial Report to the Kaiser Family Foundation. Menlo Park, CA: Kaiser Family Foundation.

Lang, J. E., Anderson, L., LoGerfo, J., Sharkey, J., Belansky, E., Bryant, L., et al. (2006). The Prevention Research Centers Healthy Aging Research Network. Preventing Chronic Dis. 3 (1), A17.

Liu, Y., and Shirley, T. (2021). Without Crossing a Border: Exploring the Impact of Shifting Study Abroad Online on Students' Learning and Intercultural Competence Development during the COVID-19 Pandemic. Online Learn. 25 (1), 182-194. doi:10.24059/olj.v25i1.2471

Makaramani, R. (2015). 21st century Learning Design for a Telecollaboration Project. Procedia-Social Behav. Sci. 191, 622-627. doi:10.1016/j.sbspro.2015.04.567

Menard-Warwick, J. (2009). Comparing Protest Movements in Chile and California: Interculturality in an Internet Chat Exchange. Lang. Intercultural Commun. 9 (2), 105-119. doi:10.1080/14708470802450487

Morgan, E. M. (2011). Associations between Young Adults' Use of Sexually Explicit Materials and Their Sexual Preferences, Behaviors, and Satisfaction. J. Sex Res. 48 (6), 520-530. doi:10.1080/00224499.2010.543960

Nava-Aguirre, K. M., Garcia-Portillo, B. I., and Lopez-Morales, J. S. (2019). "Collaborative Online International Learning (COIL): An Innovative Strategy for Experiential Learning and Internationalization at home," in The Palgrave Handbook of Learning and Teaching International Business and Management (Cham: Palgrave Macmillan), 721-746. doi:10.1007/978-3-03020415-0_34

Orsini-Jones, M., and Lee, F. (2018). "The CoCo Telecollaborative Project: Internationalisation at home to foster Global Citizenship Competences," in 
Intercultural Communicative Competence for Global Citizenship. Editors F. Lee and M. Orsini-Jones (London: Palgrave Macmillan), 39-52. doi:10.1057/978-1137-58103-7_4

Rose, I. D., Friedman, D. B., Marquez, D. X., and Fernandez, K. (2013). What Are Older Latinos Told about Physical Activity and Cognition? A Content Analysis of a Top-Circulating Magazine. J. Aging Health 25 (7), 1143-1158. doi:10.1177/ 0898264313494803

Rubin, J. (2017). Embedding Collaborative Online International Learning (COIL) at Higher Education Institutions. Internationalization Higher Educ. 2, 27-44.

Ryan, E. B., Giles, H., Bartolucci, G., and Henwood, K. (1986). Psycholinguistic and Social Psychological Components of Communication by and with the Elderly. Lang. Commun. 6, 1-24. doi:10.1016/0271-5309(86)90002-9

S. Guth and F. Helm (Editors) (2010). Telecollaboration 2.0: Language, Literacies and Intercultural Learning in the 21st century (Bern, Berlin, Bruxelles, Frankfurt am Main, New York, Oxford, Wien: Peter Lang), 1.

Soltani, S. N., Kannaley, K., Tang, W., Gibson, A., Olscamp, K., Friedman, D. B., et al. (2017). Evaluating Community-Academic Partnerships of the South Carolina Healthy Brain Research Network. Health Promot. Pract. 18 (4), 607-614. doi:10.1177/1524839917700086

Spitzer, W. O. (1997). The 1995 Pill Scare Revisited: Anatomy of a Non-Epidemic. Hum. Reprod. 12 (11), 2347-2357. doi:10.1093/humrep/12.11.2347

Tang, W., Olscamp, K., Choi, S. K., and Friedman, D. B. (2017). Alzheimer's Disease in Social media: Content Analysis of YouTube Videos. Interactive J. Med. Res. 6 (2), e19. doi:10.2196/ijmr.8612

Vahed, A., and Rodriguez, K. (2020). Enriching Students' Engaged Learning Experiences through the Collaborative Online International Learning Project. Innov. Educ. Teach. Int. 58, 1-10. doi:10.1080/14703297.2020.1792331

Walsh-Childers, K., Gotthoffer, A., and Lepre, C. R. (2002). "From "Just the Facts" to “Downright Salacious:" Teens' and Women's Magazines' Coverage of Sex and Sexual Health," in Sexual Teens, Sexual Media. Editors J. D. Brown, J. R. Steele, and K. Walsh Childers (Hillsdale, NJ: Lawrence Erlbaum), 153-171.

Ward, L. M. (2003). Understanding the Role of Entertainment media in the Sexual Socialization of American Youth: A Review of Empirical Research. Develop. Rev. 23 (3), 347-388. doi:10.1016/s0273-2297(03)00013-3
Williams, D., Kelly, A., Carvalho, M., and Feely, J. (1998). Effect of the British Warning on Contraceptive Use in the General Medical Service in Ireland. Irish Med. J. 91 (6), 202-203. doi:10.1046/j.13652133.1998.02061.x

Wood, R., Bottling, B., and Dunnell, K. (1997). Trends in Conceptions before and after the 1995 Pill Scare. Popul. Trends 89, 5-12.

Wright, H., Jenks, R. A., and Demeyere, N. (2017). Frequency of Sexual Activity in Older Adults as a Predictor of Better Working Memory Performance. Journals Gerontol. Psychol. Sci. Soc. Sci. 74 (1), 47-51. doi:10.1093/geronb/gbx065

Wright, H., and Jenks, R. A. (2016). Sex on the Brain! Associations between Sexual Activity and Cognitive Function in Older Age. Age \& Ageing 45 (2), 313-317. doi:10.1093/ageing/afv197

Wright, P. J., Malamuth, N. M., and Donnerstein, E. (2012). "Research on Sex in the media: what Do We Know about Effects on Children and Adolescents," in Handbook of Children and the Media. Editors D. G. Singer and J. L. Singer. 2nd ed. (Thousand Oaks, CA: Sage), 273-302.

Conflict of Interest: The authors declare that the research was conducted in the absence of any commercial or financial relationships that could be construed as a potential conflict of interest.

Publisher's Note: All claims expressed in this article are solely those of the authors and do not necessarily represent those of their affiliated organizations, or those of the publisher, the editors and the reviewers. Any product that may be evaluated in this article, or claim that may be made by its manufacturer, is not guaranteed or endorsed by the publisher.

Copyright (c) 2021 Ingram, Monroe, Wright, Burrell, Jenks, Cheung and Friedman. This is an open-access article distributed under the terms of the Creative Commons Attribution License (CC BY). The use, distribution or reproduction in other forums is permitted, provided the original author(s) and the copyright owner(s) are credited and that the original publication in this journal is cited, in accordance with accepted academic practice. No use, distribution or reproduction is permitted which does not comply with these terms. 